\title{
Teacher Education Model of the German Federal States: A Case of University of Berlin
}

\author{
Bacem Pikhart ${ }^{1}$, Michal Koubovská ${ }^{2}$ and AlesVaněček ${ }^{3}$ \\ ${ }^{1,2,3}$ University of Hradec Kralove, Czech Republic \\ 'bacem.pikhart@uhk.cz, ${ }^{2}$ michal.koubovska@uhk.cz.
}

\begin{abstract}
Germany is one of the first countries in the world to establish teacher education, and its teacher education system has developed relatively mature. At the same time, as a federal decentralized country, teacher education in the federal states of Germany has evolved into a system with significant regional differences due to its different social development processes. This article aims to conduct a comparative study of the typical German federal state teacher education model and discuss the handling methods of German teacher education in the internship stage. Graduates of comprehensive universities need to receive the same internship training as normal students and strengthen the quality assurance of non-teacher professional teachers. Finally, teacher education is closely linked to social, political, economic development, and other factors. We need to formulate reasonable education goals based on the actual situation, constantly adjust and update the existing teacher education system according to the development of the times, and improve teacher education through continuous feedback and improvement processes.
\end{abstract}

Keywords: German teacher education, Historical period, Educational model, Professionalism and openness

\section{Introduction}

In the early 19th century, under the influence of William Humboldt's educational thoughts, the German teacher education system gradually developed into a basic model with higher education and national unified examinations as the two cores. Teacher education was defined as a high-quality public service under the supervision of the federal state. Although German society has undergone two centuries of turbulent changes, from the Kingdom of Prussia to the Industrial Revolution, to the two world wars and the separation of the two Germanys after the war, to the Bologna process that began at the beginning of this century, the traditional concept of teacher education is very important for today's Germany. The teacher education system still has a profound impact. The federal states have gradually adjusted the teacher education system based on the historical, cultural, and socio-economic characteristics of the region, forming a rich picture of the diversification of the teacher education system nationwide.

From the beginning of the Middle Ages to the end of World War II, the Prussian government had a profound influence on the German region and continues to this day. This influence involves every aspect of society, including politics, economy, culture, environment, resources, etc., especially Prussian culture. The contribution to education was praised by

Article history:

Received (November 16, 2018), Review Result (January 1, 2019), Accepted (February 27, 2019) 
posterity. In 1717, the Kingdom of Prussia began to implement compulsory national education, becoming the first country in the world to implement compulsory education. In 1810, the first new university, the University of Berlin, was established, which had a significant impact on the development of higher education around the world. In 1890, Wilhelm von Humboldt became Prussia's highest chief of education. The reform of the educational system under his leadership laid the foundation for the later development of science and culture in Germany.

After the Napoleonic Wars, Prussia introduced the national teacher qualification certification system, and for the first time clarified the competence standards that teachers should have. The implementation of the qualification certification system greatly improved the quality of the entire country's teaching staff. In 1812, Prussia began to set up high school entrance examinations, which laid the foundation for the formal systematization and nationalization of German schools. Therefore, from the perspective of development history, the federal states that originally belonged to the Prussian region have carried out educational reforms that are relatively advanced, and the scope of reforms is also broader.

After the Second World War, Germany was geographically divided into two parts: the Federal Republic of Germany and Democratic Germany. Among them, Saxony, SaxonyAnhalt, Mecklenburg-Vorpommern, Brandenburg, Thuringia, and East Berlin belong to the jurisdiction of the former Soviet Union, while the remaining states belong to the United States, Britain, and France. Although the four countries established a joint management committee in Berlin after the war, the different political, cultural, and economic backgrounds of the Eastern and Western German governments have caused huge differences in their teacher education concepts and systems. This difference has also contributed to the diverse development of the German teacher education system. Due to the profound influence of the former Soviet Union's teacher education philosophy, the eastern GDR region generally adopts a one-stage teacher education model. Teachers are mostly ordinary employees who sign employment contracts. However, the government attaches great importance to the organic combination of teacher professional education and teaching practice and cultivates Most of the teachers have higher literacy. The occupation army in West Germany adopts a two-stage teacher education and training system, and all teachers have the status of civil servants. The West German government attaches great importance to the unification of teacher qualifications and examination standards. Therefore, it has issued several related documents for teacher education, including the "Principles for the Qualification Examination of Liberal Arts Secondary School Teachers" and the "December 21, 1988, the relevant member states of the European Community set at least 3 Recommendations on the pre-employment education stage and mutual recognition of higher education diplomas" etc. [1]. The differences between East and West Germany's teacher education systems are obvious. The GDR pays more attention to the traditional teacher education training model, while West Germany actively imitates the new teacher education models of other countries in Europe and America, and vigorously promotes the process of unification and internationalization.

Since the signing of the Bologna Declaration in 1999, the process of European education integration has been continuously adjusted and expanded. Germany, as the first signatory, has conducted a large number of reform attempts in the field of higher education, including teacher education, including German Minister of Education and Culture The "Standards for Teacher Education" issued by the Joint Conference (KMK) in 2004 [2] clarified the competence standards that teachers must have; KMK adopted the "Uniform Professional Knowledge and Teaching Requirements for Teacher Education in Each State" in 2008 and 2012 respectively." And "Uniform Internship and National Examination Requirements of 
Each State" and "Adaptability Evaluation Recommendations for the First Stage of Teacher Education" issued in 2013. However, these policies currently issued by KMK are only programmatic documents, which can only serve as a consultation and suggestion function for the implementation of specific teacher education plans, and do not make clear requirements on whether each region retains the original teacher education system or introduces a new bachelor and master education system This has caused the difference between the leading and lagging states of the federal states in the process of European integrated education reform.

\section{The overall structure of the German teacher education model}

Since Germany began to implement teacher education reform across the country [3], the reform models and levels adopted by the federal states have been uneven. Up to now, 16 federal states have adopted a "two-stage" teacher education system, that is, the first stage of professional theoretical knowledge learning of teacher education in colleges and universities, including an internship semester. In the second stage, internship training is carried out in the teacher training center. The teacher education model under this unified system can be divided into two categories-the traditional national examination model and the bachelor/master grading model. The bachelor/master grading model can be divided into two types: specialization and diversification. Coupled with the parallelism of the traditional national examination model and the grading model, the German teacher education model can be divided into the following four categories, see [Table 1].

Table 1. Classification of teacher education models implemented in each federal state in Germany

\begin{tabular}{|c|c|c|c|}
\hline $\begin{array}{c}\text { National Unified } \\
\text { Examination }\end{array}$ & \multicolumn{2}{|c|}{ Bachelor's Shunshi Grading Model } & Mixed mode \\
\hline Traditional (modular) & Diversification & Specialization & \\
& Berlin & & \\
& Niedersachsen & & Sachsen-Anhalt Baden- \\
Wurttemberg Saarland \\
Mecklenburg Bayern & Nordrhein-Westfalen & & \\
Shachsen & Thuringen & Brandenburg Hamburg Hessen \\
& Rheinland-Pfalz & & \\
& Bremen & & \\
& Schlesweig-Holstein & & \\
\hline
\end{tabular}

\subsection{Professional and diversified two-stage training model}

Most federal states have begun to implement a two-stage teacher education for bachelor/master. Bachelor's and master's degrees are independent, professionally qualified first- and second-level degrees. Bachelor's and master's courses can be studied in different types of universities. There are two types of bachelor's degrees: one is a professional bachelor's, and the other is a multiple bachelor. At the time of enrolment, students studying for a professional bachelor's have clearly defined their education career and prepared for the subsequent master of education study. They mainly study educational courses focusing on education science, professional teaching theory, and teaching practice, and then deepen and expand students at the master's level. Under this training model, after obtaining a bachelor's degree, students can also undertake increasing work in the field of education and training outside of secondary schools. In the undergraduate study stage, students studying for multiple bachelors' courses are mainly based on professional subjects. At the bachelor level, students only have initial contact and understanding of the teaching profession. They need to decide whether to engage in the teaching profession in the future at the graduation stage. The training 
required for teacher professionalization is mainly carried out at the master stage. This diverse bachelor's degree model gives students more choice. However, under the appeal of KMK, there are differences in the bachelor's degree training model implemented in various regions, especially in the curriculum of multiple bachelor's degrees; the proportion of education majors is not consistent in different regions [4].

\subsection{National unified examination training model}

As a traditional teacher education model in Germany, the unified national examination only exists in a few federal-state normal universities, and these universities have also begun to organize and arrange training courses in a modular form. Students need to finish each module study and take the unified exam.

\subsection{Mixed culture mode}

Some federal states have adopted the coexistence of traditional and new teacher training methods. Universities in the Thuringia region have adopted both the modular national examination path and the bachelor/master's graded training path. Due to the reform pilot measures adopted in North Rhine-Westphalia, universities and colleges have introduced new training models to varying degrees, so they also belong to this column.

The essence of the above four teacher education models is a game between several extreme models - integrating teacher education and staged teacher education, as well as the professionalization and generalization of teacher education. The reasons for this regional difference can be attributed to multiple levels: First, the paths of reforms implemented by the federal states are different, including the reform policies issued by the states and the timing of the implementation of the reforms. Secondly, the inherent educational traditions of the federal states are also an important factor in the formation of this differentiation of teacher education models [5]. Finally, the gradual weakening and abolition of the original national unified teacher qualification examination system have further deepened the differentiation of this teacher education model. The existing teacher education standards have shown more and more diversified characteristics under the framework of modularization and credit system [6].

\section{Comparative analysis of German teacher education models}

Based on the above analysis of the diversified social and historical factors of teacher education in Germany, due to the differences in regional development, some federal states still adhere to a more traditional professional teacher education model, while other federal states have implemented comprehensive teacher education training. Although the Federal Ministry of Education has issued a series of policy documents to integrate and unify the standards and goals of teacher education in various states, it remains open to the specific measures and paths of teacher education in various regions, that is, to continue to maintain the diversity of teacher education in Germany. As you can see from the table above, Bavaria is one of the few regions in Germany that fully retain the traditional teacher education model. According to a survey report of the Institute for Education Development [7], in the 2016 IQB Education Trend Test, Bavarian primary and secondary school students ranked among the top in the two subject tests of mathematics and German. At the same time, Berlin, as one of the first regions to carry out teacher education reform, took the lead in implementing a degree grading system and curriculum modularization. However, as a pioneer of reform, the quality of regional education was not satisfactory. In the IQB test, student performance was lagging 
national average shown in [Table 2]. Based on the above reasons, to have a deeper understanding of the differences between the two models, this paper selects the typical teacher education models of the two federal states-Bavaria and Berlin as the research objects and focuses on professional learning in the two federal states. Compare and analyze the teacher education model in the two stages of internship training.

Table 2. Student performance and teacher education models in Berlin and Bavaria

\begin{tabular}{|c|c|c|c|c|c|}
\hline \multirow{2}{*}{ Federal states } & \multicolumn{2}{|c|}{ German } & \multicolumn{2}{c|}{ Math } & \multirow{2}{*}{$\begin{array}{c}\text { Types of teacher } \\
\text { education models }\end{array}$} \\
\cline { 2 - 5 } & $\begin{array}{c}\text { Student } \\
\text { performance } \\
\text { (average) }\end{array}$ & $\begin{array}{c}\text { Standard } \\
\text { deviation }\end{array}$ & $\begin{array}{c}\text { Student } \\
\text { performance } \\
\text { (average) }\end{array}$ & $\begin{array}{c}\text { Standard } \\
\text { deviation }\end{array}$ & Open type \\
\hline Berlin & 475 & 110 & 446 & 110 & Professional \\
\hline Bavaria & 514 & 93 & 508 & 96 & . \\
\hline
\end{tabular}

\subsection{Berlin's teacher education model}

Berlin is the capital of Germany and the largest city in Germany. It is the only three citystates in Germany along with Hamburg and Bremen. Due to its special history of the division of East and West Germany, Berlin's demand for educational reforms to promote regional integration and unification has become even stronger. In the process of system reform of teacher education and school structure, Berlin, Bremen, and Hamburg were the first federal states to carry out teacher education reforms. Berlin first introduced a bachelor/master grading model in 2004, and implemented a new teacher education in 2014 Law, the main contents of the amendments include: unifying the length of education for all types of teacher education; improving the professionalism of primary school teaching (German and mathematics as compulsory subjects). Teachers in inclusive schools must obtain special education qualifications. Add an internship semester to strengthen the proportion of practice in the study stage. Establish a central institution to strengthen the importance of teacher education in colleges and universities [8].

The types of teacher education in Berlin include elementary school teachers, comprehensive middle school and liberal arts middle school teachers, and vocational school, teachers. All types of teacher education have fully adopted the bachelor/master grade model. The prescribed study period for bachelor's degree courses is 6 semesters (180 credits), The prescribed study period for the master's degree program in 4 semesters $(120$ credits). At present, the Free University of Berlin (FU), Humboldt University of Berlin (HU), Technical University of Berlin (TU), and University of the Arts Berlin (UdK) undertake the task of regional teacher education. Major universities and colleges carry out teacher education in various specialties according to their professional characteristics. Training work. The University of Arts is mainly responsible for the training of music and fine arts education; the University of Technology is responsible for the training of economics, engineering, and technical education such as civil engineering, electrical engineering, metal technology, nutritional food science, agricultural gardening, etc.; Humboldt University is mainly responsible for economics, education, and training in business subjects such as accounting and charge of sports and special education. The Berlin Teacher Education Steering Committee, as the state-level central coordinating body, macro-controls the educational work of all state college teacher education centers.

Since the 2004/2005 winter semester, the educational courses at the professional learning stage have been transformed into modular degree courses that are closely related to teaching positions and adopt credit certification. The teacher education curriculum includes three parts: 
professional subjects, subject teaching, and educational science. Starting from the 2015/2016 winter semester, the credit requirements for the education major of Berlin elementary school teachers have increased to 195, including the teaching major (75) and the other two majors (120); the pedagogy course has a total of 60 credits, consisting of education science (30), elementary school pedagogy (20) and language education (10); both the bachelor's and master's stages include internship semesters, with a total of 30 internship credits. Starting from the 2016/2017 winter semester, the teaching practice consists of 3 professional courses and a study and research project.

The undergraduate study stage is not divided into majors according to the target school type, and teacher education is included in unified professional learning. Undergraduate study courses are divided into courses including digital publishing, computer management, and information competence in a modular form. These curriculum themes are in harmony with the new requirements of the modernization process for teachers' competence. Modular education format helps to better distribute learning content and exam focus and has a positive meaning in promoting targeted individual education. Starting from the 2016/2017 winter semester, an internship semester has been introduced into the four-semester master's program, through practical training, trying to combine students' theoretical study with practice. The purpose of the practical semester is to improve teaching planning, implementation, and reflection skills, and to better transition to the second phase of the teacher training-the internship phase. In addition, in the process of completing the study and research project, students need to have an in-depth understanding of all aspects of school education based on theoretical research and data analysis, to promote the professional development of future teachers [9].

The requirement from the study stage to the internship stage is to obtain a master's degree in teacher education or pass the first national unified qualification examination. Starting in 2014, the duration of each category of teachers in the practice phase has been extended to 18 months. There is only one stage of teacher teaching practice training in Berlin, and the training is also carried out in the form of curriculum modularization, with a maximum of 10 lessons per week. The internship training content is divided into two modules: curriculum and educational innovation, in addition to a 30-class introductory seminar course [10]. In general, whether it is practical education during study or training courses at the internship stage, Berlin teacher education has begun to consciously increase the proportion of the practical part to enhance the continuity of teacher theoretical learning and practical training. The evaluation method of practical training is conducted in the form of an open class. All types of teacher education evaluations require two trial lectures. The two-module courses each account for $20 \%$. The examination format can be from written assignments, slides, oral exams, and speech exams. Choose two. In addition, the average score accounts for $20 \%$, and the two professional courses account for $20 \%$ respectively.

Berlin has always been positive on the road of teacher education reform and has made many attempts. Its characteristics are as follows:

(1) Take the lead in implementing the bachelor/master graded training model, improve the openness of teacher education, allow college students to make professional adjustments according to their development in the learning stage, and at the same time improve the mobility of learning between regions. On this basis, Berlin took the lead in introducing a policy that allows non-educational college graduates to directly apply for internship training and can also serve as teachers after passing the second national examination. The abovementioned policies have enriched the structure of Berlin's teaching staff, and at the same time put forward higher requirements for the local teacher quality assurance mechanism. 
(2) Innovate the modular reform of teacher education curriculum, take different professional abilities of teachers as topics, proceed from the laws of professional development, pay attention to the cultivation of basic general professional abilities of teachers, and conform to the development of the times, and constantly add modules that meet new requirements Courses. This "wide base, flexible module" curriculum is suitable for cultivating comprehensive talents.

(3) In the process of teacher reform in Berlin, the training of teacher education has gradually weakened the learning of specialized teaching theory knowledge, combined pedagogy, and professional subject learning, and focused on improving the formulation of teacher education standards and teacher quality Evaluation.

\subsection{Teacher education model in Bavaria}

Bavaria is currently the only federal state in Germany that still retains the traditional national examination model. In the wave of national teacher education reform, Bavaria has innovated the content and form of teaching according to its actual conditions [11]. In 2006, the Bavarian Teacher Education Law was revised, and the teacher education curriculum was modularized based on retaining the first national examination system while emphasizing the importance of teaching methods and practical content. In 2016, under the promotion of the teacher education quality offensive, Bazhou raised the standards for trainee teachers to enter the second phase of training to ensure the high quality of regional teacher education.

All universities in Bavaria have teacher education centers or institutions of the same level. The types of teacher education they provide include elementary schools, liberal arts middle schools, vocational schools, and special school teaching positions. Except for teaching posts in vocational schools, other types of teacher education still follow the traditional model of national examinations. The prescribed learning time limit and requirements of each teacher education category are different. For example, for primary school teachers and middle school teachers, there are 7 semesters (210 ECTS) for teachers, and 9 semesters for teachers in liberal arts and sciences (270 ECTS). According to the teaching requirements of students of different abilities and various types of teacher education, a diversified teacher education system in Bavaria has been constructed. For example, most elementary and middle school teachers serve as head teachers and teach a variety of subjects. Therefore, pedagogy, pedagogy, and psychology are extremely important for elementary and secondary school teacher education. At the same time, they should also master other professional subjects such as German and mathematics. In contrast, in physical middle schools and liberal arts middle schools, the focus is on in-depth research on professional subjects. Therefore, this type of teacher education should pay more attention to the training of professional subjects and related subjects, and at the same time, it should be combined with education, pedagogy, and psychology.

Teacher education in Bavaria continues the traditional model. Students must decide the type of school they will teach in the future before enrolling, and cannot change it at will during the study period. After graduation, they can only work in that type of school and professional subject. Taking the first category of teacher education as an example, Bavaria's primary school teacher education requires a study time limit of 7 semesters and a total of 210 credits. The specific course settings are as follows: subject professional courses total 54 credits; teaching methods account for 82 credits, of which 70 credits are for elementary school teaching methods, and the remaining 12 credits are mainly for subject teaching; education courses account for 43 credits, of which 8 credits are for sociology courses. It also 
includes 31 credits for internships, graduation thesis, and other electives. Before enrollment, students must participate in a 3-4week admission practice and an 8-week business practice. In addition, the teacher education stage also covers 150-160 hours of teaching practice (6 ECTS), subject teaching practice, and primary school practice. However, due to the short duration of teacher education in Bavaria, and the state level has not made clear regulations for the internship stage, it has not introduced clear regulations on the content of internships in the teacher training stage.

Bavaria's requirements for entering the internship phase include passing the first national unified qualification examination or obtaining a master's degree in education in other states. The teacher education practice training phase lasts for 24 months. The practical training is divided into two stages, each for 12 months. The first stage is conducted in the training institution, and students must participate in a 10-hour seminar every week; in the second stage, normal students will begin teaching practice in primary and secondary schools. The training forms include seminar courses, independent practice, teaching internships, and training courses. The training content is divided into professional subject teaching (5 hours/week), pedagogy (1.5 hours/week), psychology (1.5 hours/week), school law (0.5 hours/week), and other related courses ( 0.5 hours/week). The teacher education practice training in Bavaria divides the stages of theoretical study, seminars, and exchanges, and practical teaching, emphasizing that practical teaching is based on a solid theoretical foundation, and emphasizes the cultivation of skills transferability in teaching practice. The assessment methods for the internship stage include a trial lecture with a double assessment system and a trial lecture, oral examination (education and psychology seminars, subject teaching, school law, basic issues of civic education), written assignments (pedagogy, psychology, subject teaching methods). The evaluation score is obtained by the average score of teaching ability, education ability, and practical ability. The trial score is composed of two trial scores and the average score of the oral test. The total score is composed of the evaluation score, the trial score, the oral test score, and the symposium score and written assignment scores.

Since Bavaria has completely continued the traditional national examination model, it is difficult to completely transform the teacher training curriculum into an educational structure that meets the Bologna standards, and the parallelism of two completely incompatible educational systems will lead to inefficient use of educational resources in universities and system interruptions. The relatively closed teacher education model requires normal students to clarify their teaching goals when entering colleges and universities, and stick to their chosen major during the entire seven-year normal course of study. In this context, Bazhou has greatly reduced the shortcomings of this closed teacher education model through a strict admissions selection system, while ensuring the professionalism of teachers in the region.

Bazhou teacher education attaches great importance to the periodic characteristics of professional education and clarifies the knowledge and skill requirements that teacher students should learn at each stage. In the theoretical study stage, pedagogy, pedagogy, and professional subject courses are reasonably allocated according to the talent training plan, and the connection between practical courses and theoretical courses is emphasized, and specific regulations are made for pre-and post-course to make the courses effective Cohesion runs through the entire professional stage of learning. While Bavaria insists on conducting national examinations, it also pays attention to the cooperation between education departments and universities, and at the same time, takes into account international and national development, and strives to achieve an integrated Bavarian teacher training program. The university's teacher training center and teacher education research center serves as internal and external 
coordination and interface, by ensuring the communication between the various departments and the school supervision agency and the connection of all stages of teacher education, for the further professionalization of teacher training courses Make an indispensable contribution. If the future teacher education center is structurally well integrated into all fields of teacher education and can coordinate all participants in a goal-oriented manner, it will further improve the quality of teacher education.

\subsection{Comparison of teacher education models between Berlin and Bavaria}

Berlin is a pioneer of a new model of teacher education. The state only provides a bachelor/master teacher training model. During the study, the teacher education curriculum weakens the oriented professionalism, and the comprehensive ability of students is improved through curriculum modularization; the internship phase, is an extended Practice period, thus connecting with other states. In addition, the practical courses also apply a modular training model, which is conducive to students' learning in training institutions and internships in service schools at the same time [12].

Bavaria, as the only existing federal state in Germany that only implements the traditional teacher education training model, has also opened up teacher education entrances to other federal states based on protecting the original unified national examination model. During the study, teacher education courses show strong specialization characteristics from the beginning of enrollment. Educational professional courses in the curriculum are relatively large, and it is more difficult for students to switch majors during the learning process; in the internship stage, Bavaria divides Normal students emphasize the professional foundation of teachers' teaching in the stage of internship in training institutions and primary and middle schools.

In summary, there are certain differences between the Berlin teacher education characterized by an open system and modularity and the Bavarian teacher education characterized by a professional system and integration in terms of training models and curriculum settings shown in [Table 3]. Berlin's teacher education system is in line with the new trend of modern education - the integrated training of integrated education talents. From a macro perspective, the teacher education system that is unified with other European countries has also greatly improved the cross-regional teacher education system. With the mobility of study and work, this open education model gives students greater freedom in all stages of learning; from a micro point of view, the modular curriculum of Berlin teacher education makes up for the shortcomings of its shorter academic system. Improve the effectiveness and practicality of students' professional learning. Bazhou continues the traditional teacher education model, insisting on maintaining the professionalism of teacher education, and emphasizing the training of education professional ability. The teachers trained under this model have strong teaching ability and research level, and the comprehensive curriculum is important for normal students. The combination of professional disciplines and teaching knowledge is more stimulating and can better integrate theory and practice organically. For modern education, the above two teacher education models have some parts worth learning. 
Table 3. Comparison of teacher education systems between Berlin and Bavaria

\begin{tabular}{|c|c|c|}
\hline Educational stage & Berlin & Bavaria \\
\hline Study stage & $\begin{array}{c}\text { Bachelor: 6 semesters } \\
\text { Method 195ECTS Education Course 60ECTS } \\
\text { Teaching }\end{array}$ & $\begin{array}{c}\text { 7 semesters (210 ECTS) Professional } \\
\text { Course 54 ECTS Teaching Method } \\
\text { 82 ECTS Education Course 43 ECTS } \\
\text { Other 31 ECTS }\end{array}$ \\
\hline $\begin{array}{c}\text { Internship 30ECTS Other 35 ECTS } \\
\text { Entry criteria for the second } \\
\text { stage }\end{array}$ & $\begin{array}{c}\text { Master's degree certificate } \\
\text { Out-of-state personnel need to pass the first } \\
\text { national examination for entry }\end{array}$ & $\begin{array}{c}\text { The first national exam } \\
\text { required for entry of out-of-state } \\
\text { personnel }\end{array}$ \\
\hline Internship stage & $\begin{array}{c}\text { 18 months: one stage (modular course) } \\
\text { Teacher system type }\end{array}$ & $\begin{array}{c}\text { 24 months: the first stage (training } \\
\text { class); the second stage (school } \\
\text { internship) }\end{array}$ \\
\hline Open Modular & Specialization Staged \\
\hline
\end{tabular}

\section{Conclusion}

Education not only has its own rules of operation but is also affected by factors such as social political and economic development. In addition to the comprehensive teacher education training system that will have an important impact on the work of teachers, other environmental factors such as the status and treatment of teachers in the region also determine teachers. For example, Berlin teachers are not national civil servants, and their salaries are lower than in other federal states. Therefore, the loss of teachers is serious. The state government has begun to hire non-teacher students to solve the problem of teacher shortage. Focusing only on the teacher education model and implementation in the two regions, Berlin has caused an imbalance in regional education development due to historical reasons. Under this background, the government hopes to unify various types of education systems through reforms, without careful consideration. Germany's traditional professional education is rapidly transitioning to the general education recommended by the European Union, and its drawbacks are slowly emerging. In the 2019 National Education Quality Test, Berlin ranks last in the fields of school quality, higher education, and academic research. The Bavarian model of teacher education continuously adjusts itself on the road of adhering to the traditional model of teacher education to adapt to the requirements of the development of the times for teachers. The teacher education in Ba State has proved its value in school education. This traditional teacher education model is not by its nature stubbornly standing still, but constantly improving and adjusting itself according to the actual situation. Continuously carry out corresponding developments by current requirements, and continue to integrate and integrate the successful experience of other regions and even other countries. Each model has its advantages and disadvantages and has its specific aspects. Only by choosing a suitable model and a reasonable path can the desired training goal be achieved.

\section{References}

[1] B. Walsh, S. Nixon, and C. Walker, "Using a clean feedback model to facilitate the learning process," Creative Education, vol.6, no.10, pp.953-960, (2015)

[2] C. Cooperation, "The culture of immigrant populations and cultural policies: Socio-cultural innovations in the member states of the CDCC," Summary of the Meeting (Strasbourg, France, March 4-5, 1986). The CDCC's Project No.7: The Education and Cultural Development of Migration 
[3] M. Pugah, "The national education reports and special education: Implications for teacher preparation," Exceptional Children, vol.53, no.4, pp.308

[4] Y. Noh, I. J. Ahn, and S. K. Choi, "A study of changes in the library and information science curriculum with the evaluation of its practicality," Journal of Academic Librarianship, vol.38, no.6, pp. 348-364, (2012)

[5] K. V. Lee, "Resolving the dissonant constitutional chords inherent in the federal anti-bootlegging statute in united states v. moghadam[J]," Jeffrey S Moorad Sports Law Journal, (2000)

[6] S. Halima, "Societal perception of repositioning childhood education through mother tongue: Prospects and challenges in Northwest Nigeria[J]," International Journal of Scientific Research and Management, vol.6, no.8, (2018)

[7] W. Rolf, D. Peters, and R. Lenz, "Farmland - an elephant in the room of urban green infrastructure? Lessons learned from connectivity analysis in three German cities," Ecological Indicators, 1.94P2, no.NOV, pp.151163, (2017)

[8] D. Dustin, L. Browne, and K. Bricker, "Strengthening the relationship between undergraduate professional preparation programs in parks, recreation, and tourism and graduate leisure studies," SCHOLE: A Journal of Leisure Studies and Recreation Education, vol.26, no.1, pp.21-29, (2017)

[9] L. Hagger-Vaughan, "How schools in England understand and enact education policy: The case of modern languages at key stage 4," (2018)

[10] Touger-Decker, Riva, "Nutrition education of medical and dental students: innovation through curriculum integration," American Journal of Clinical Nutrition, vol.79, no.2, pp.198-203, (2004)

[11] H. Simone, F. Dominik, and T. S. Margarete, "First assessment for the presence of phlebotomine vectors in Bavaria, Southern Germany, by combined distribution modeling and field surveys," Plos One, vol.8, no.1, pp. 81088, (2013)

[12] Haberlin, Steven, "Something always works: A self-study of strengths-based coaching in supervision," Journal of Educational Supervision, vol.2, no.1, pp.3, (2019) 
Teacher Education Model of the German Federal States: A case of University of Berlin

This page is empty by intention. 